Discussion Paper No. 664

\title{
EXPERIMENTS ON RISK ATTITUDE: THE CASE OF CHINESE STUDENTS
}

\author{
Shunichiro Sasaki \\ Shiyu Xie \\ Fumio Ohtake \\ Jie Qin \\ and \\ Yoshiro Tsutsui
}

June 2006

The Institute of Social and Economic Research

Osaka University

6-1 Mihogaoka, Ibaraki, Osaka 567-0047, Japan 


\title{
Experiments on Risk Attitude:
}

\section{The Case of Chinese Students}

\author{
Shunichiro Sasaki ${ }^{\mathrm{a}}$, Shiyu Xie ${ }^{\mathrm{b}}$, Fumio Ohtake ${ }^{\mathrm{a}}$, \\ Jie Qin ${ }^{c}$, Yoshiro Tsutsui ${ }^{\text {a* }}$ \\ ${ }^{a}$ Osaka University, Institute of Social and Economic Research, 6-1 Mihogaoka, Ibaraki, \\ Osaka 567-0047, Japan \\ ${ }^{\mathrm{b}}$ Fudan University, Department of World Economics, 220 Handan Road, \\ Shanghai 200433, P. R. China \\ ${ }^{\mathrm{c}}$ Ritsumeikan University, Faculty of Economics, 1-1-1 Noji-higashi, Kusatsu, \\ Shiga 525-8577, Japan
}

*Corresponding author: Phone: +81-6-6879-8560, Fax: +81-6-6878-2766

Email Addresses: ssasaki@iser.osaka-u.ac.jp (S. Sasaki), syxie@fudan.edu.cn (S. Xie), ohtake@iser.osaka-u.ac.jp (F. Ohtake), jieqinjp@yahoo.co.jp (J. Qin), tsutsui@econ.osaka-u.ac.jp (Y. Tsutsui) 


\begin{abstract}
This paper examines Chinese students' risk attitude using buying and selling experiments with lotteries. We found that subjects were more risk averse in the buying experiment than in the selling experiment, suggesting the endowment effect. In the selling experiment, subjects were risk loving when there was a low win probability and risk averse with a high win probability, whereas they were risk averse in the buying experiment. Using the prize money won during the experiment as a measure of wealth, we found decreasing absolute risk aversion. Subjects' risk attitude as revealed in the experiments explains their risky asset holding behavior.

JEL classification: C91, D81
\end{abstract}

Keywords: risk aversion, economic experiment, China 


\section{Introduction}

This paper examines Chinese students' risk attitude by using buying and selling experiments with lotteries, based on the BDM method (Becker et al., 1964). Experiments in China are especially interesting in that prizes won by subjects are relatively large compared to those in developed countries because of the high purchasing power of the Chinese yuan. It is often argued that economic experiments are not reliable because prizes are too small to give subjects an adequate incentive. Experiments in China might be immune to such a criticism. ${ }^{1}$ Indeed, the cost of living in 2005 was 6.5 times lower for our Chinese subjects than for Japanese subjects after an exchange rate conversion. ${ }^{2}$ Nevertheless, to our knowledge, there have been few such experiments in China. ${ }^{3}$

Our experiment is unique in that we conducted both a buying and a selling experiment with the same subjects. Previous studies conducted selling experiments (Kachelmeier and Shehata, 1992, Eichberger et al., 2003) and buying experiments (Cramer et al., 2002, Shavit et al., 2001, Hartog et al., 2002) separately. However, to our knowledge, no studies have examined both selling and buying experiments

\footnotetext{
${ }^{1}$ Another response to this criticism is to use the results of TV shows that pay huge prizes. Fullenkamp et al. (2003) and Beetsma and Schotman (2001) reported that people are risk averse, while Metrick (1995) does not reject the proposition that they are risk neutral.

${ }^{2}$ This figure is based on responses to our questionnaire from subjects of the experiment done in Shanghai and Tokyo. We asked the cost of living per month.

${ }^{3}$ Kachelmeier and Shehata (1992) were a notable exception. They conducted an experiment to measure risk attitude and found that the risk attitude of Chinese subjects did not differ from that of subjects in the US and Canada. They are risk loving for lotteries with a small win probability and risk neutral otherwise.
} 
comprehensively. ${ }^{4}$ Comparing the results of previous studies based on selling and buying experiments, one could argue that subjects participating in buying experiments were more risk averse than those in selling experiments. However, it is not convincing to draw the conclusion that people are more risk averse when they sell lottery tickets than when they buy them, as the difference may be due to a difference in subject characteristics. Thus, it is important to conduct an experiment where the same subjects participate in both buying and selling experiments.

Our study was also unique in that we asked the subjects to answer a detailed questionnaire that included scenario questions on risk attitude. We analyzed how risk attitude related to their demographic and economic attributes such as knowledge of financial economics and wealth. Although Barsky et al. (1997), Donkers et al. (2001), and Hartog et al. (2002) examined these relationships using questionnaire surveys, our method has merit in that we measured risk attitude in a controlled experiment where subjects had monetary incentives. We examined whether subjects' risk attitudes can explain their risky asset holdings. We also investigated whether subjects’ risk attitudes as revealed in the experiments were consistent with those in the questionnaire. Finally, we examined how subjects' risk aversion correlated with their time discount rates, which was measured in our experiment.

The rest of the paper is organized as follows. In the next section, we explain our experimental method. In Section 3, we show the risk attitude according to probability of

\footnotetext{
${ }^{4}$ Knetsch and Sinden (1984) is a notable exception. Their TEST3 consists of buying and selling experiments which ask similar questions to ours. However, they are different from ours in that different subjects are used for buying and selling experiments.
} 
winning a lottery and compare the results with those of Kachelmeier and Shehata (1992). In Section 4, we investigate how risk attitude relates to the attributes of the subjects. In Section 5, we analyze whether subjects' risk attitudes can account for their actual behaviors. In Section 6, we compare the risk attitude revealed in the experiment and in the questionnaire. In Section 7, we examine the relationship between time discount rate and risk aversion. Section 8 concludes.

\section{Experimental method}

The experiment was conducted on March 11, 2005, at Fudan University in Shanghai. Subjects were 30 undergraduate students of the Department of World Economics at Fudan University. ${ }^{5}$ Their attributes are summarized in Table 1. Out of 30 subjects, 26 (86\%) were female. The subjects were 20 or 21 years old. Their income and wealth was widely dispersed; household income ranged from less than 20,000 yuan (US\$2,400) to over 220,000 yuan (US\$26,400) and the mode was 20,000 (US\$2,400) to 40,000 yuan (US\$4,800).

[Table 1 about here]

The experiment on risk attitude started at $6 \mathrm{pm}$ and ended around $8 \mathrm{pm}$. An experiment on time discounting was then conducted until $9 \mathrm{pm}$. The subjects were then requested to complete a test on financial economics and fill in a questionnaire. As for the test, refer to Appendix A. The session finished around $10 \mathrm{pm}^{6}$

\footnotetext{
${ }^{5}$ One subject felt unwell and left after the selling experiment was completed, so that the number of the subjects for the buying experiment was 29.

${ }^{6}$ According to teachers and students at Fudan University, the students there study until around $10 \mathrm{pm}$
} 
The experiment was based on the BDM method as follows.

Selling experiment: Subjects were given a lottery ticket by which they receive 1000 points if they win and nothing otherwise. The win probability was set randomly by the computer in each round. After subjects put their selling price into the computer, the computer showed its buying price, which was determined randomly. If the buying price exceeded the selling price, the lottery ticket was traded at the buying price. Otherwise, subjects retained their tickets and the computer determined the win or lose randomly following the win probability. Subjects who won got 1000 points. Subjects who lost received nothing. The subjects recorded their results in each round in order to check the results and to have time to consider their strategies. This procedure was repeated for five rounds as practice and for 20 rounds as real sessions. At the end, the points obtained in the real sessions were summed and converted to yuan with 1000 points equal to 20 yuan (US\$2.4); that amount was paid at the end of all the experiments on that day.

Buying experiment: The buying experiment was the same as the selling experiment with the following exception. Subjects were given 10,000 points at the outset. ${ }^{7}$ They input their buying price (the highest value that they could offer) for a lottery ticket for which the win probability was shown on their own

every day, so the evening experiment was not a burden to them. We conducted the experiment in the evening because it was difficult to recruit students during for daytime experiments as they were expected to attend classes.

${ }^{7}$ This is necessary because in selling experiment subjects were given 20 lottery tickets with the expected payoff of 10,000 points. Furthermore, subjects would have been too embarrassed to buy a lottery ticket if they had no points at the outset. 
display. If this buying price exceeded the selling price offered by the computer, the ticket was traded to the subject at the selling price. In this case, if they won, the payoff was the 1000 points minus the selling price; if they lost, they suffered a loss equal to the selling price.

Points won by subjects and their converted payoffs in yuan are presented in Table 2. The average payoff was 261 yuan (US\$31, 13,033points) for the selling experiment and 260 yuan (US\$31, 12,977 points) for the buying experiment. ${ }^{8}$

[Table 2 about here]

\section{Risk attitudes in the selling and buying experiment}

We adopted the following measure of absolute risk aversion (ARA) developed in Cramer et al. (2002):

$$
A R A=\frac{a Z-p}{1 / 2 \times\left(a Z^{2}-2 a p Z+p^{2}\right)},
$$

where $Z$ is the lottery prize, $p$ is the price evaluated by a subject, and $a$ is the win probability. We also present the result of the "transformed risk averse price (TP)" defined as:

$$
T P=1-\frac{p}{a Z}
$$

To compare our results with those in Kachelmeier and Shehata (1992), we calculated the average $A R A$ and $T P$ for each category of win probability, $0-10 \%, 10$ $20 \%$, and so on. The results are presented in Figures $1-4$, where the horizontal axis

\footnotetext{
${ }^{8}$ In addition to payoffs, subjects received a 120 yuan (US\$14) participation fee.
} 
represents the win probability and the vertical axis represents $A R A$ or $T P$.

[Figure 1 about here]

Figure 1 shows TP for the selling experiment, which corresponds to Figures 1 and 2 in Kachelmeier and Shehata (1992). ${ }^{9}$ These figures appear superficially similar. The subjects were risk loving in lotteries with win probabilities of less than $20 \%$ and almost risk neutral in the others. Close examination, however, reveals a difference. As Figure 1 in our paper shows, subjects were risk averse in the lotteries with win probabilities of over 30\%, at the 5\% significance level, whereas Kachelmeier and Shehata (1992) reported that the subjects were at most risk neutral. ${ }^{10}$ Kachelmeier and Shehata's result was important because subjects facing very high rewards in the experiment were risk loving or neutral, implying that these characteristics did not appear just because they were gambling for smaller amounts of money. Indeed, they show that the subjects were risk loving in lotteries with small prizes, but risk neutral in lotteries with large prizes, implying that the subjects became more risk averse as prizes became larger. If subjects' risk attitudes vary depending on the amount of prizes as they observed, it would be possible to interpret our results as meaning that our subjects show a risk-averse attitude because the prize was very large. The average prize won by the subjects was 632 yuan (US\$76) while they reported that their average monthly living expenses were 2048 yuan (US\$246); subjects therefore earned on average one third of their monthly living

\footnotetext{
${ }^{9}$ Note that Kachelmeier and Shehata (1992) show the certainty-equivalent ratio, which is equivalent to 1TP.

${ }^{10}$ They do not show the confidence interval, so that we cannot evaluate the significance of their results.
} 
expenses in two hours. ${ }^{11}$ Our results cast a doubt on Kachelmeier and Shehata (1992)'s finding: people may be risk averse in lotteries with a win probability greater than $30 \%$.

If we adopt the other risk measure, $A R A$, the risk-averse attitudes become more evident. In Figure 2, the subjects were risk loving only in lotteries with win probabilities of less than $10 \%$. They were risk neutral in lotteries with win probabilities of $10-50 \%$, and risk averse in those of over $60 \% .{ }^{12}$ Specifically, it seems that they became more risk averse with higher win probabilities.

[Figure 2 about here]

Figures 3 and 4 show the results of the buying experiments. ${ }^{13}$ These results are quite different from those in Figures 1 and 2. Specifically, the subjects showed riskaverse attitudes in lotteries with any win probability, which is consistent with the usual assumptions of economic theory.

[Figures 3 and 4 about here]

To check whether the difference between risk attitudes in selling and buying experiments is significant, we regressed the risk attitude variables ( $A R A$ and $T P$ ) over the win probability $(P R O B)$ and the buying dummy variable $(B U Y)$, which is set at unity for buying experiments and zero for selling experiments. We pooled all the data, 20 rounds for each of the selling and buying experiments multiplied by the number of

\footnotetext{
${ }^{11}$ According to a teacher at Fudan University, most Chinese students' living expenses per month should be under or around 1000 yuan (US\$120). If this is true, our prize is tantamount to more than half their monthly living expenses.

12 These results are the same as those from Japanese experiments. See Tsutsui et al. (2005).

${ }^{13}$ In the calculation of $A R A$ data, we excluded one sample because the subject assigned 999 points to a lottery with a win probability of $100 \%$, leading to an extreme value of 2 .
} 
subjects, and estimated fixed effects and random effects models.

The estimation results are presented in the first and second columns of Table 3. Here, we show the results of a random effects model for the case of $A R A$; the random effects model was not rejected against the fixed effects model on the basis of the Hausman specification test. However, for the case of $T P$, the results of the fixed effects model are shown because the random effects model was rejected at the $1 \%$ significance level. The estimated coefficients of $P R O B$ are always positive and significant, implying that the subjects show more risk-averse attitudes to lotteries with higher win probabilities. This can be seen in Figure 2 ( $A R A$; selling experiment), whereas Figure 4 (ARA; buying experiment) does not show this tendency. Regression analysis of combined data from both experiments confirms the tendency. The coefficients of BUY are significantly positive for both cases, indicating that the subjects are significantly more risk averse in buying experiments than in selling.

\section{[Table 3 about here]}

Figures 1-4 reveal differently shaped graphs in many aspects between selling and buying experiments; e.g., $A R A$ and $T P$ are decreasing in win probability in buying experiments, while they are increasing in the selling experiments. To confirm the differences, we added $P R O B^{2}, B U Y^{*} P R O B, P R O B^{2}$, and $B U Y^{*} P R O B^{2}$ into the regression equation. The estimation results are shown in the third and fourth columns of Table 3. $A R A$ and $T P$ are increasing in $P R O B$ in the selling experiments, while $A R A$ is decreasing in the buying experiments. The tendency is not clear in the case of $T P$ in the buying experiments. $A R A$ and $T P$ are concave in the selling experiments, while $A R A$ is convex and $T P$ is concave in the buying experiments. These results are also confirmed 
by the estimation splitting the samples between the selling and buying experiments (see columns 5-8 in Table 3).

The finding that subjects are risk averse in buying experiments has been reported in Shavit et al. (2001), Hartog et al. (2002), and Cramer et al. (2002). In addition, the finding that subjects are risk loving or risk neutral in selling experiments has been reported in Kachelmeier and Shehata (1992) and Eichberger et al. (2003). Our experimental results confirm that subjects exhibit different risk attitudes in selling and buying lotteries even when the same subjects participated in both experiments.

Why does risk attitude differ between selling and buying experiments? One argument is that the subjects learned the structure of the experiments and the optimal strategy during the selling experiment that was conducted before the buying experiment, so that they revealed their true attitude in the buying experiments. However, this interpretation is not very convincing because the amount of money won by the subjects did not differ between experiments, leading us to reject the notion of a learning effect. Another possible interpretation for higher risk aversion in the buying experiment is the endowment effect (Kahneman et al., 1990). Among other studies, Knetsch and Sinden (1984) observed that subjects’ willingness to accept (WTA) in a lottery was higher than their willingness to pay (WTP), which implies that they were more risk averse when they bought a lottery ticket than when they sold one. Our finding is consistent with this endowment effect.

\section{How does the risk attitude relate to attributes of the subjects?}

In this section, we examine how the risk attitude revealed in the experiments 
relates to the socioeconomic attributes of the subjects. Specifically, we focus on wealth, knowledge of financial economics, and gender.

How risk attitude depends on wealth has been an important topic. Arrow (1970) argues decreasing absolute risk aversion and increasing relative risk aversion with respect to wealth. As for absolute risk aversion, using the results of a questionnaire survey, Hartog et al. (2002) find decreasing absolute risk aversion with respect to respondents' annual income. Based on survey results, Donkers et al. (2001) also report that risk aversion decreases as income increases, although they do not use absolute risk aversion as the risk measure. In an experiment in which subjects invest money into risky projects, Levy (1994) found decreasing absolute risk aversion and decreasing (or constant, at most) relative risk aversion with respect to wealth varying during the experiment. As for relative risk aversion, most studies measure relative risk aversion using the risky asset holding ratio, and decreasing relative risk aversion has been reported instead (Cohn et al., 1975, Guiso et al., 1996, and Kessler and Wolf, 1991).

The effect of education on risk attitude has been also studied. Donkers et al. (2001) and Hartog et al. (2002) report that subjects with higher education levels tend to be more risk loving. In this paper, the subjects are all university students, and our aim was to investigate the effect of knowledge of financial economics on their risk attitude. As standard finance theory is based on the assumption that economic agents are risk averse, students who study finance theory may believe that they must behave as if they are risk averse. To test this hypothesis, after the experiments we requested the subjects to complete a test that consisted of seven economics problems including three on risk aversion. We analyzed the relationship between the test score and risk attitude. 
As in the previous section, we pooled all the data, 40 rounds multiplied by the number of subjects, and estimated fixed and random effects models with them. Because some of the subjects did not answer questions about their income and assets, their observations were dropped from the estimation. Win probability (PROB) and the dummy variable representing the buying experiment (BUY) are considered in the regression analysis, as risk attitude is systematically influenced by these, as shown in the previous section.

For the gender variable, we adopted a dummy variable MALE, which takes the value of unity if the subject is a male, and zero otherwise. For the variable representing knowledge on financial economics, we adopted TEST, which is the score of the subjects on the test conducted immediately after the experiment. For the wealth data, we considered three different variables, INCOME, ASSETS, and POINTS, whose definitions will be explained below.

The results of the random effects model are shown in Table 4 for the cases of ARA and TP because the Hausman specification test does not reject random effects models against fixed effects models. In the first and second columns, the results when ASSETS is adopted as the wealth variable are shown, where ASSETS is the logarithm of the amount of financial and real assets owned by a subject's household. $P R O B$ and $B U Y$ are significantly positive, confirming the results in Table 3. TEST is positive, but insignificant. MALE is negative, but only significant in the TP case. ASSETS is positive, but insignificant. This unexpected result might be because ASSETS includes assets owned by the subjects' parents. ASSETS probably does not represent most subjects' personal wealth. 


\section{[Table 4 about here]}

Considering the above problem, we adopted INCOME, which is defined as the logarithm of subjects' annual income including support from their parents. The results are presented in the third and fourth columns. $P R O B, B U Y$, and $M A L E$ produce similar results to the case of ASSETS. TEST is positive and significant at around the $10 \%$ level here. INCOME is negative as expected, but insignificant.

A problem with INCOME may be that it is constant for all the rounds of the experiments, whereas risk attitude measured as $A R A$ or $T P$ differed between rounds. Meanwhile, actual wealth of the subjects was also changed by the prizes they won in each round. We should not neglect this change in wealth during the experiment, which the subjects confirmed on their PC monitors in each round; they also wrote the value on their record sheets. According to the prospect theory (Kahneman and Tversky, 1979), subjects may recognize the outset of the experiment as the "reference point" and focus on the change in wealth resulting from wins and losses in each lottery.

In the fifth and sixth columns, we present the results with POINTS adopted as the wealth variable, where POINTS is the cumulative total of points that subjects had won before each round of the experiment. The effect of INCOME, which varies only among subjects, if at all, may be captured in individual constant terms. POINTS is significantly negative as expected, implying decreasing absolute risk aversion. The coefficients of the other variables are similar to the results obtained when INCOME or ASSETS are used.

INCOME, which represents the level of wealth before the experiment, may have an additional effect to POINTS on risk attitude. To examine this possibility, we included both POINTS and INCOME as the wealth variables. The results, which also include 
ASSETS, are shown in the seventh and eighth columns of Table 4. POINTS is again negative and significant. INCOME is still insignificant, but its $P$-value increases to $15 \%$ for the ARA case. ASSETS is again positive but not significant. These results confirm the conclusion that absolute risk aversion is decreasing in wealth.

Arrow (1970) argued that relative risk aversion ( $R R A)$ may be increasing with wealth. However, the empirical evidence is not decisive. Although most of the studies on relative risk aversion adopted the risky asset holding ratio as the measure of relative risk aversion, our study is unique in that we used the more direct measure of relative risk aversion derived from the pricing of lotteries. We constructed $R R A$ by multiplying ARA by POINTS, and regressed it against POINTS (representing wealth), PROB, and BUY. ${ }^{14}$ The results are presented in the ninth column of Table 4. POINTS is not significant, implying constant relative risk aversion. We repeated the analysis using $R R A$ defined as $A R A \times \exp (A S S E T S)$ and $A R A \times \exp (I N C O M E)$ to obtain similar results. These results suggest that relative risk aversion is constant with respect to wealth, supporting the conventional use of the constant relative risk averse (CRRA) utility function in macrofinance.

Let us summarize the results of the other variables. The coefficient of $P R O B$ is always significantly positive, implying that the subjects are more risk averse in lotteries with higher win probabilities. The coefficient of $B U Y$ is always significantly positive, confirming the estimation results in the preceding section. The coefficient of MALE is always negative but significant at the $5 \%$ level only when the dependent variable is $T P$.

\footnotetext{
${ }^{14}$ As the fixed effects model is chosen by the Hausman specification test, MALE and TEST are dropped in the estimation.
} 
The observation that males are more risk loving than females is consistent with the findings of Barsky et al. (1997), Donkers et al. (2001), and Hartog et al. (2002), all of which were based on questionnaire surveys.

The coefficient of TEST is always positive but significant at the $10 \%$ level only when the dependent variable is $A R A$ and when INCOME was utilized as the wealth variable. Although this result is not strong, it suggests that students who have more knowledge of financial economics are likely to be more risk averse. Levy and Levy (2001, 2002) measured risk attitudes of business school students and practitioners (fund managers and financial analysts) to find that practitioners were more risk averse than students. As practitioners would have more knowledge about financial economics than students, these results are consistent with ours. Meanwhile, Donkers et al. (2001) and Hartog et al. (2002) reported that subjects with higher education levels tend to be more risk loving. Thus, a consistent interpretation is that higher general education levels make people more risk loving, but specific knowledge of financial economics makes people more risk averse.

\section{Subjects' risky asset holdings and their risk attitudes}

Can risk attitude revealed in the experiment explain subjects' actual behavior? In this section, we investigate the relationship between subjects' risk attitudes and their risky asset holdings. We postulate that more risk-averse subjects have smaller proportions of risky assets, and we test this hypothesis with our data.

As for the risky asset holdings, we asked the following question in the questionnaire completed at the end of the experiment. 
What percentage of the financial assets of your entire household are in Investment Trusts, Stocks, Futures/Options, Corporate Bonds, Foreign Currency Deposits, Government Bonds of Foreign Countries?

Let us define the variable RISK as the percentage that subjects reported in response to this question. As the variable for risk attitude for each subject, we define AVARA and $A V T P$ as the average $A R A$ and average $T P$ over the 40 rounds in the selling and buying experiments.

We regressed RISK against AVARA (or AVTP), ASSETS (or INCOME), and MALE. ${ }^{15}$ The estimation results are shown in Table 5. Tobit was used for the estimation because one subject answered that she had no risky assets. ${ }^{16}$ The estimated coefficients of AVARA were significantly negative, supporting our hypothesis, while those of AVTP were negative but insignificant.

[Table 5 about here]

This is somewhat surprising, considering that AVARA represents the subjects' risk attitude, while the risky asset holding ratio is usually determined by their parents. Thus, to understand this result, we need to assume that risk attitudes of parents and children correlate. Is this assumption reasonable? The answer is "yes.” Indeed, Hirata et al. (2006) conducted a questionnaire survey of parents and their children and found that the correlation coefficient between the risk aversion of parents and their children was 0.18

\footnotetext{
${ }^{15}$ We do not use POINTS as the wealth variable here because risky asset holding has nothing to do with the change in wealth during the experiments.

${ }^{16}$ The results by OLS are almost the same as those in Table 5.
} 
when lottery questions were used. ${ }^{17}$ Thus, the finding of negative correlation between parents' risky asset holding ratio and children's absolute risk aversion may be reasonable.

ASSETS is significantly positive, whereas INCOME is positive but insignificant. This result is reasonable because ASSETS comprises assets owned by the household, whereas INCOME is the income of the subjects (i.e., the children). The risky asset holding ratio of a household may relate more strongly to the former than to the latter.

However, the positive correlation between RISK and ASSETS is not consistent with the theoretical model of Friend and Blume (1975). They developed a model based on the Capital Asset Pricing Model (CAPM) in which the proportion of risky assets to total assets (RISK) is equal to the ratio of expected excess return $\left(r_{m}-r_{f}\right)$ and variance of return on the market portfolio $\left(\sigma_{m}{ }^{2}\right)$ divided by relative risk aversion $(R R A)$. That is:

$$
\text { RISK }=\frac{\left(r_{m}-r_{f}\right)}{\sigma_{m}{ }^{2} R R A} \text {. }
$$

Most previous researchers, including Friend and Blume (1975) themselves, relied on this relation to use risky asset share $(R I S K)$ as a proxy for risk tolerance $\left(\frac{1}{R R A}\right)$ and examined how RRA relates to the wealth. Thus, in their analyses, if relative risk aversion is increasing with respect to wealth, risky asset share should negatively relate

\footnotetext{
${ }^{17}$ The sample size was 260, so the correlation coefficients were significant (5\% critical value is 0.12 ). Hirata et al. (2006) report that the correlation coefficient between time discount rates of parents and their children is around 0.2 , while the correlation coefficient between random pairs who have no relationship is zero.
} 
to the wealth. However, in many cases, the opposite is detected, indicating that the relation does not describe reality (e.g. MacCarthy (2004)) $)^{18}$

Our paper is unique in that we can test the relation between risky asset share and $R R A$ because we have data on absolute risk aversion as well as the wealth. As relative risk aversion is absolute risk aversion multiplied by wealth, Friend and Blume’s (1975) model predicts that the share of risky assets negatively correlates with ARA and ASSETS, when both of them are included in regression equation to explain RISK. This is indeed what we report in Table 5. Although our result is consistent with the model in that ARA negatively correlates to the share, it does not support the model because the coefficient of ASSETS is significantly positive. Our results suggest that use of risky asset share as a proxy for $R R A$ may be problematic. Moreover, we found that $R R A$ is constant with respect to the wealth in the preceding section, implying that RISK would have been constant with respect to the wealth, if Friend and Blume's (1975) model is true. The fact that RISK positively correlates to the wealth suggests the rejection of their model.

A problem of this estimation is that ASSETS consists of real asset and financial asset, while RISK is defined as the ratio to financial asset only. Thus, it may be appropriate to estimate the equation adopting financial asset (FINASSETS) instead of ASSETS. The results are shown in the far right columns of Table 5. The results generally confirm the above conclusion: that $A V A R A$ is significantly negative at the $10 \%$ level and FINASSETS is positive, even if it is not significant at the $10 \%$ level.

\footnotetext{
${ }^{18}$ Friend and Blume (1975) themselves reported that risky asset share positively correlates to financial assets. However, when wealth is defined as the total of financial and real assets, they found the negative correlation.
} 
The risky asset holding of male subjects is higher than that of female subjects (32.6\% vs. 22.2\%), and males are less risk-averse than females (AVARA is 0.09 vs. 0.58 ). However, MALE is positive but insignificant in Table 5, implying that the higher risky asset holding of males is due to their lower risk aversion and nothing else.

\section{Subjects' risk attitude in experiments and in the questionnaire}

In the questionnaire completed at the end of the experiment, we asked several questions to elicit subjects' attitudes toward various types of risk. Specifically, we asked:

When you go out, how high does the probability of rain usually have to be before you take an umbrella?

We define the variable $R A I N$ as $100-\mathrm{x}$, where $\mathrm{x}(\%)$ is the answer to this question. We also asked:

One proverb, “Nothing ventured, nothing gained," reveals a belief that it is necessary to take risks if you expect excellent results. On the other hand, another proverb, “A wise man never courts danger,” reveals a belief that you should avoid risks as much as possible. Which way of thinking is closest to yours? On a scale of $0-10$ with " 10 ” being completely in agreement with the former statement, and “ 0 " being completely in agreement with the latter statement, please rate your behavioral pattern.

We define VENTURE as $10-\mathrm{x}$, where $\mathrm{x}$ is the answer to this question.

Another question was: 
When you go out, are you usually careful about locking doors/windows and turning off appliances to prevent a fire? On a scale of $0-10$ with " 10 ” being the "least careful”, and “0” being the "most careful”, please rate your level of caution.

We define FIRE as $10-\mathrm{x}$, where $\mathrm{x}$ is the answer to this question.

Questions 13-16 asked the subjects their subjective price in various lotteries, which are similar to the trials in the experiment. Specifically, in Q13 subjects were asked what their buying price would be in a lottery with a prize of 160 yuan (US\$19) with a win probability of 50\%. Question 14 asked their buying price in a lottery with the prize of 8000 yuan (US\$960) with a win probability of 1\%. Question 15 asked the selling price of the lottery in Q13. Question 16 asked about insurance against losses instead of a lottery. Specifically, we asked:

Assume that you know there is a $1 \%$ chance of being robbed of 8000 yuan (US\$960). However, you can take out an insurance policy that covers losses from a robbery. How much would you pay for this insurance?

For Q13-Q16, we calculated the ARA and TP for each subject. The correlation coefficient between AVARA in the experiment and risk attitude in the questionnaire is shown in the first column in the top panel of Table 6.

[Table 6 about here]

AVARA revealed in the experiment significantly correlated with RAIN and VENTURE, but it did not significantly correlate with FIRE. AVARA has a relatively high correlation with $Q 13 A R A$ and $Q 15 A R A$, which are the most similar questions to that in the experiment. These results imply that the risk attitudes revealed in the experiments 
and in the questionnaire are generally consistent. ${ }^{19}$

At the same time, however, the results in Table 6 suggest that risk attitude varies substantially depending on the types of risk asked about. The correlation between AVARA and Q14ARA is almost zero. These two questions ask about risk attitudes in quite different situations: the prize in Q14ARA was very large (8000 yuan (US\$960)), while the prize in the experiment was only 20 yuan (US\$2.4). The correlation between Q16ARA and AVARA is also close to zero. These two questions are also quite different. In Q16ARA, subjects were asked their subjective price of insurance where the possible loss was very large (8000 yuan (US\$960)), while attitude towards an uncertain small gain (20 yuan (US\$960)) is asked in the experiment.

In sum, although one may expect all the variables in Table 6 to be highly correlated because they all represent risk attitude, this is not the case at all. The risk attitude is quite different depending on the type of risk.

This finding is confirmed if we look at the correlations between items in the questionnaire instead of looking at the correlations between those in the experiment and in the questionnaire. In the top panel of Table 6, a positive correlation is significant at the $5 \%$ level in only three cases out of $28^{20}$. This result may be due to the following reasons. One is that the measures based on psychological questions, RAIN, VENTURE, and FIRE, ask about attitudes toward different types of risks. Rain risk is a small risk,

\footnotetext{
${ }^{19}$ Therefore, the low correlation mentioned below is not due to the difference in methods (experiment and questionnaire).

${ }^{20}$ Only one case is significant out of 21 cases between items in the questionnaire, which is, the correlation between the most similar questions (Q13 and Q15).
} 
while fire risk is a large risk, and people may show different attitudes depending on the risk size. The second possible reason, already argued above, is that Q13 and Q14 have different win probabilities and different prizes, which results in the different risk attitudes demonstrated in Section 3. Question 16 is concerned with insurance against an expected loss, while Q13-Q15 are concerned with the evaluation of an expected gain. Thus, "loss aversion” proposed in Kahneman and Tversky (1979) produces a different risk attitude. If the difference is not identical among the subjects, correlation will be weak or even negative.

In the bottom panel of Table 6, we show the correlation between AVTP of the experiment and several variables from the questionnaire. Here, AVTP in the experiment has a positive correlation with all the measures in the questionnaire, although it is insignificant. Most of the correlation coefficients are positive, but they are not significant, confirming the results of AVARA.

\section{Risk aversion negatively correlates with time discount rate}

In this section, we examine the relationship between time discounting and risk aversion. The time discount rate is calculated from the results of an experiment conducted after the experiment on risk attitude. Let us briefly explain the experiment on time discount rate.

Subjects were asked to choose whether they would prefer to (A) receive $u$ yuan after $x$ months (or $x^{\prime}$ days) or (B) receive $v$ yuan after $y$ months (or $y^{\prime}$ days). We fix $u, x$, and $y$, and change $v$ from a small amount to a large amount for 32 pairs to find the point at which the subjects switch from A to B. Let us call the interest rate corresponding to 
this switching $R$ (\%). Higher $R$ indicates a higher discount rate. We conducted the experiments for 12 pairs of $(u, x, y)$ including experiments with and without prizes, so that there are 12 items of data on $R$ for each subject ${ }^{21}$. We take the logarithm of these $R \mathrm{~s}$ and average them $(T D)$.

The correlation between the time discount rate TD and AVARA is -0.274 , and that between $T D$ and $A V T P$ is -0.114 . They are negative, although insignificant, suggesting that less patient people may tend to be less risk averse. The negative correlation between the time discount rate and risk aversion is also reported in Hiruma and Tsutsui (2005) and Tsutsui et al. (2005), who based their findings on experiments with Japanese subjects. Thus, the observation may be a robust fact, even if the correlation is not strong. The reason for this observation is an interesting question for future investigation.

\section{Conclusion}

In this paper, we present the results of an experiment on risk attitudes conducted at Fudan University in Shanghai. First we investigated how risk attitude depends on win probabilities of lotteries. The results of the selling experiment were similar to those of Kachelmeier and Shehata (1992) in that risk-loving attitudes with a win probability of less than $20 \%$ were confirmed. However, subjects held risk-averse attitudes when win probability exceeded 30\%. Thus, Kachelmeier and Shehata's results need to be reconsidered.

In buying experiments, subjects showed risk-averse attitudes for all win probabilities. We found that subjects were more risk averse in buying experiments than

\footnotetext{
${ }^{21} 12$ pairs of $(u, x, y)$ are shown in Appendix B.
} 
in selling experiments, which is generally consistent with previous literature. Our results are unique in that this tendency is confirmed even when the same subjects participated in both the selling and the buying experiments. The higher risk aversion in buying experiments can be interpreted as an endowment effect, as proposed in Knetsch and Sinden (1984) and Kahneman et al. (1990).

Using the data from the questionnaire completed after the experiment, we observed that (1) males may be more risk loving than females, (2) those who have more knowledge of financial economics are more risk averse, and (3) absolute risk aversion is decreasing and relative risk aversion is constant with respect to change in wealth.

Subjects' risk attitudes revealed in the experiments can account for their risky asset holding. The risk attitudes revealed in the experiment are generally consistent with those revealed in the questionnaire, but risk attitudes are different depending on various types of risks. Finally, we find a negative correlation between risk aversion and time discount rate.

\section{Acknowledgments}

This research was supported by the 21st Century COE program at Osaka University and Grant-in-Aid for Scientific Research 17203025 of the Ministry of Education, Culture, Sports, Science and Technology in Japan. 


\section{References}

Arrow, K. J., 1970. Essays in the theory of risk-bearing. North-Holland: Amsterdam.

Barsky, R. B., Juster, F. T., Kimball, M. S., Shapiro, M. D., 1997. Preference parameters and behavioral heterogeneity: an experimental approach in the health and retirement study. Quarterly Journal of Economics 112(2), 537-579.

Becker, G. M., Degroot, J., Marschak, J., 1964. Measuring utility by a single response sequential method. Behavioral Science 9, 226-232.

Beetsma, R. M. W.-J., Schotman, P. C., 2001. Measuring risk attitudes in a natural experiment: data from the television game show Lingo. Economic Journal 111, 821-848.

Cohn, R. A., Lewellen, W. G., Lease, R. C., Schlarbaum, G. G., 1975. Individual investor risk aversion and investment portfolio composition. Journal of Finance 30, 605-620.

Cramer, J. S., Hartog, J., Jonker, N., Van Praag, C. M., 2002. Low risk aversion encourages the choice for entrepreneurship: an empirical test of a truism. Journal of Economic Behavior and Organization 48, 29-36.

Donkers, B., Melenberg, B., Van Soest, A., 2001. Estimating risk attitudes using lotteries: a large sample approach. Journal of Risk and Uncertainty 22(2), 165-195.

Eichberger, J., Guth, W., Muller, W., 2003. Attitudes towards risk: an experiment. Metroeconomica 54(1), 89-124.

Friend, I., Blume, M. E., 1975. The demand for risky assets. American Economic Review 65(5), 900-922.

Fullenkamp, C., Tenorio, R., Battalio, R., 2003. Assessing individual risk attitudes using field data from lottery games. Review of Economics and Statistics 85(1), 218-226.

Guiso, L., Jappelli, T., Terlizzese, D., 1996. Income risk, borrowing constraints, and portfolio choice. American Economic Review 86, 158-172.

Hartog, J., Carbonell, F. I., Jonker, N., 2002. Linking measured risk aversion to individual characteristics. Kyklos 55 (1), 3-26.

Hirata, K., Ohtake, F., Tsutsui, Y., 2006. Is time preference inherited? mimeo.

Hiruma, F., Tsutsui, Y., 2005. Are people really risk-averse?: an experimental study. Osaka Economic Papers 55 (2), 43-68 (in Japanese).

Kachelmeier, S. J., Shehata, M., 1992. Examining risk preference under high monetary incentives: experimental evidence from the People's Republic of China. American 
Economic Review 82(5), 1120-1141.

Kahneman, D., Tversky, A., 1979. Prospect theory: an analysis of decision under risk. Econometrica 47, 263-291.

Kahneman, D., Knetsch, J. L., Thaler, R., 1990. Experimental tests of the endowment effects and the Coase theorem. Journal of Political Economy 98, 1325-1348.

Kessler, D., Wolf, E. N., 1991. A comparative analysis of household wealth patterns in France and the United States. Review of Income and Wealth 37, 249-266.

Knetsch, J. L., Sinden, J. A., 1984. Willingness to pay and compensation demanded: experimental evidence of an unexpected disparity in measures of value. Quarterly Journal of Economics 99, 507-521.

Levy, H., 1994. Absolute and relative risk aversion: an experimental study. Journal of Risk and Uncertainty 8(3), 289-307.

Levy, M., Levy, H., 2001. Testing for risk aversion: a stochastic dominance approach. Economic Letters 71, 233-240.

Levy, M., Levy, H., 2002. Experimental test of the prospect theory value function: a stochastic dominance approach. Organizational Behavior and Human Decision Processes 89, 1058-1081.

McCarthy, D., 2004. Household portfolio allocation: a review of the literature. mimeo.

Metrick, A., 1995. A natural experiment in “Jeopardy!” American Economic Review 85, 240-253.

Shavit, S., Sonsino, D., Benzion, U., 2001. A comparative study of lotteries-evaluation in class and on the web. Journal of Economic Psychology 22, 483-491.

Tsutsui, Y., Ohtake, F., Ikeda, S., 2005. Estimation of degree of risk aversion: an experiment at Osaka University. mimeo (in Japanese). 
Table 1. Attributes of the subjects

\begin{tabular}{|c|c|c|c|c|c|c|c|}
\hline & & Frequency & Ratio & & & Frequency & Ratio \\
\hline \multirow{3}{*}{ Gender } & Male & 4 & 0.13 & \multirow{3}{*}{ Age } & 20 & 14 & 0.47 \\
\hline & Female & 26 & 0.86 & & 21 & 13 & 0.43 \\
\hline & & & & & NA & 3 & 0.1 \\
\hline \multirow{12}{*}{$\begin{array}{l}\text { Own annual } \\
\text { income }\end{array}$} & None & 2 & 0.07 & \multirow{12}{*}{$\begin{array}{l}\text { Household's } \\
\text { real estate }\end{array}$} & $<100,000$ & 3 & 0.1 \\
\hline & $<1,000$ & 1 & 0.03 & & $\begin{array}{c}100,000- \\
200,000\end{array}$ & 4 & 0.13 \\
\hline & $\begin{array}{c}1,000- \\
2,000\end{array}$ & 3 & 0.1 & & $\begin{array}{c}200,000- \\
400,000\end{array}$ & 3 & 0.1 \\
\hline & $\begin{array}{c}2,000- \\
4,000\end{array}$ & 1 & 0.03 & & $\begin{array}{c}400,000- \\
600,000\end{array}$ & 5 & 0.17 \\
\hline & $\begin{array}{c}4,000- \\
6,000\end{array}$ & 3 & 0.1 & & $\begin{array}{c}600,000- \\
800,000\end{array}$ & 2 & 0.07 \\
\hline & $\begin{array}{c}6,000- \\
8,000\end{array}$ & 3 & 0.1 & & $\begin{array}{l}800,000- \\
1,000,000\end{array}$ & 2 & 0.07 \\
\hline & $\begin{array}{l}8,000- \\
10,000\end{array}$ & 2 & 0.07 & & $\begin{array}{c}1,000,000- \\
1,200,000\end{array}$ & 3 & 0.1 \\
\hline & $\begin{array}{c}10,000- \\
12,000\end{array}$ & 2 & 0.07 & & $\begin{array}{c}1,200,000- \\
1,400,000\end{array}$ & 1 & 0.03 \\
\hline & $\begin{array}{c}12,000- \\
14,000\end{array}$ & 3 & 0.1 & & $\begin{array}{c}1,400,000- \\
1,600,000\end{array}$ & 0 & 0 \\
\hline & $\begin{array}{c}14,000- \\
16,000\end{array}$ & 3 & 0.1 & & $>1,600,000$ & 1 & 0.03 \\
\hline & $>16,000$ & 1 & 0.03 & & NA & 6 & 0.2 \\
\hline & NA & 6 & 0.2 & & & & \\
\hline
\end{tabular}




\begin{tabular}{|c|c|c|c|c|c|c|c|}
\hline & $<20,000$ & 2 & 0.07 & & $<20,000$ & 4 & 0.13 \\
\hline & $\begin{array}{c}20,000- \\
40,000\end{array}$ & 8 & 0.27 & & $\begin{array}{c}20,000- \\
40,000\end{array}$ & 2 & 0.07 \\
\hline & $\begin{array}{c}40,000- \\
60,000\end{array}$ & 3 & 0.1 & & $\begin{array}{c}40,000- \\
60,000\end{array}$ & 2 & 0.07 \\
\hline & $\begin{array}{l}60,000- \\
80,000\end{array}$ & 3 & 0.1 & & $\begin{array}{l}60,000- \\
80,000\end{array}$ & 0 & 0 \\
\hline & $\begin{array}{l}80,000- \\
100,000\end{array}$ & 2 & 0.07 & & $\begin{array}{l}80,000- \\
100,000\end{array}$ & 0 & 0 \\
\hline & $\begin{array}{c}100,000- \\
120,000\end{array}$ & 0 & 0 & & $\begin{array}{c}100,000- \\
120,000\end{array}$ & 8 & 0.27 \\
\hline \multirow[t]{7}{*}{$\begin{array}{l}\text { Household's } \\
\text { annual income }\end{array}$} & $\begin{array}{c}120,000- \\
140,000\end{array}$ & 0 & 0 & $\begin{array}{l}\text { Household's } \\
\text { financial assets }\end{array}$ & $\begin{array}{c}120,000- \\
140,000\end{array}$ & 0 & 0 \\
\hline & $\begin{array}{c}140,000- \\
160,000\end{array}$ & 1 & 0.03 & & $\begin{array}{c}140,000- \\
160,000\end{array}$ & 1 & 0.03 \\
\hline & $\begin{array}{c}160,000- \\
180,000\end{array}$ & 0 & 0 & & $\begin{array}{c}160,000- \\
180,000\end{array}$ & 0 & 0 \\
\hline & $\begin{array}{c}180,000- \\
200,000\end{array}$ & 0 & 0 & & $\begin{array}{c}180,000- \\
200,000\end{array}$ & 0 & 0 \\
\hline & $\begin{array}{c}200,000- \\
220,000\end{array}$ & 1 & 0.03 & & $\begin{array}{c}200,000- \\
220,000\end{array}$ & 2 & 0.07 \\
\hline & $>220,000$ & 3 & 0.1 & & $>220,000$ & 0 & 0 \\
\hline & NA & 7 & 0.23 & & NA & 11 & 0.37 \\
\hline
\end{tabular}

Note: Income and assets are in yuan. Own annual income includes spouse's income and support by parents. Household income/assets include own income/assets and those of parents. 
Table 2. Points and payoffs won by the subjects

\begin{tabular}{|c|c|c|c|c|c|c|}
\hline & & $\begin{array}{l}\text { Number of } \\
\text { subjects }\end{array}$ & Average & $\begin{array}{l}\text { Standard } \\
\text { deviation }\end{array}$ & Minimum & Maximum \\
\hline Selling & Points & 30 & 13033 & 1564 & 10183 & 16699 \\
\hline experiment & $\begin{array}{l}\text { Payoffs } \\
\text { in yuan }\end{array}$ & 30 & 261 & 31 & 204 & 334 \\
\hline Buying & Points & 29 & 12997 & 1148 & 10804 & 15786 \\
\hline experiment & $\begin{array}{l}\text { Payoffs } \\
\text { in yuan }\end{array}$ & 29 & 260 & 23 & 217 & 316 \\
\hline & Points & 30 & 25597 & 2983 & 12812 & 29282 \\
\hline Total & $\begin{array}{l}\text { Payoffs } \\
\text { in yuan }\end{array}$ & 30 & 512 & 60 & 257 & 586 \\
\hline
\end{tabular}

Note: Points won in the buying experiment include 10,000 points given to the subjects at the outset of the buying experiment. In addition to payoffs above each subject is given 120 yuan as the participation fee. 
Table 3. Risk attitude, win probability, and endowment effect

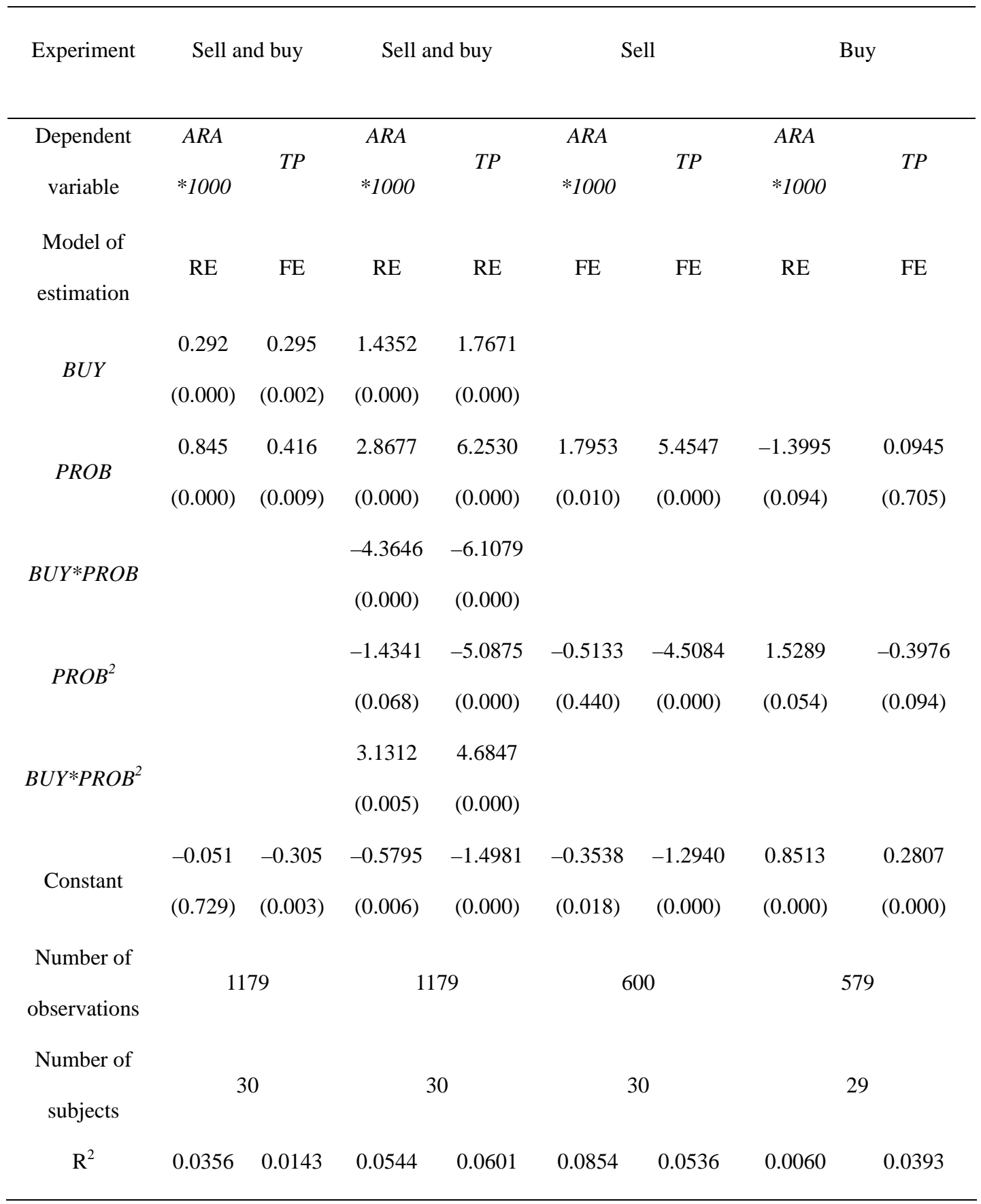

Note: $P$-values are in parentheses. RE represents random effects model; FE represents fixed effects model. 
Table 4. Risk attitude and subjects' attributes

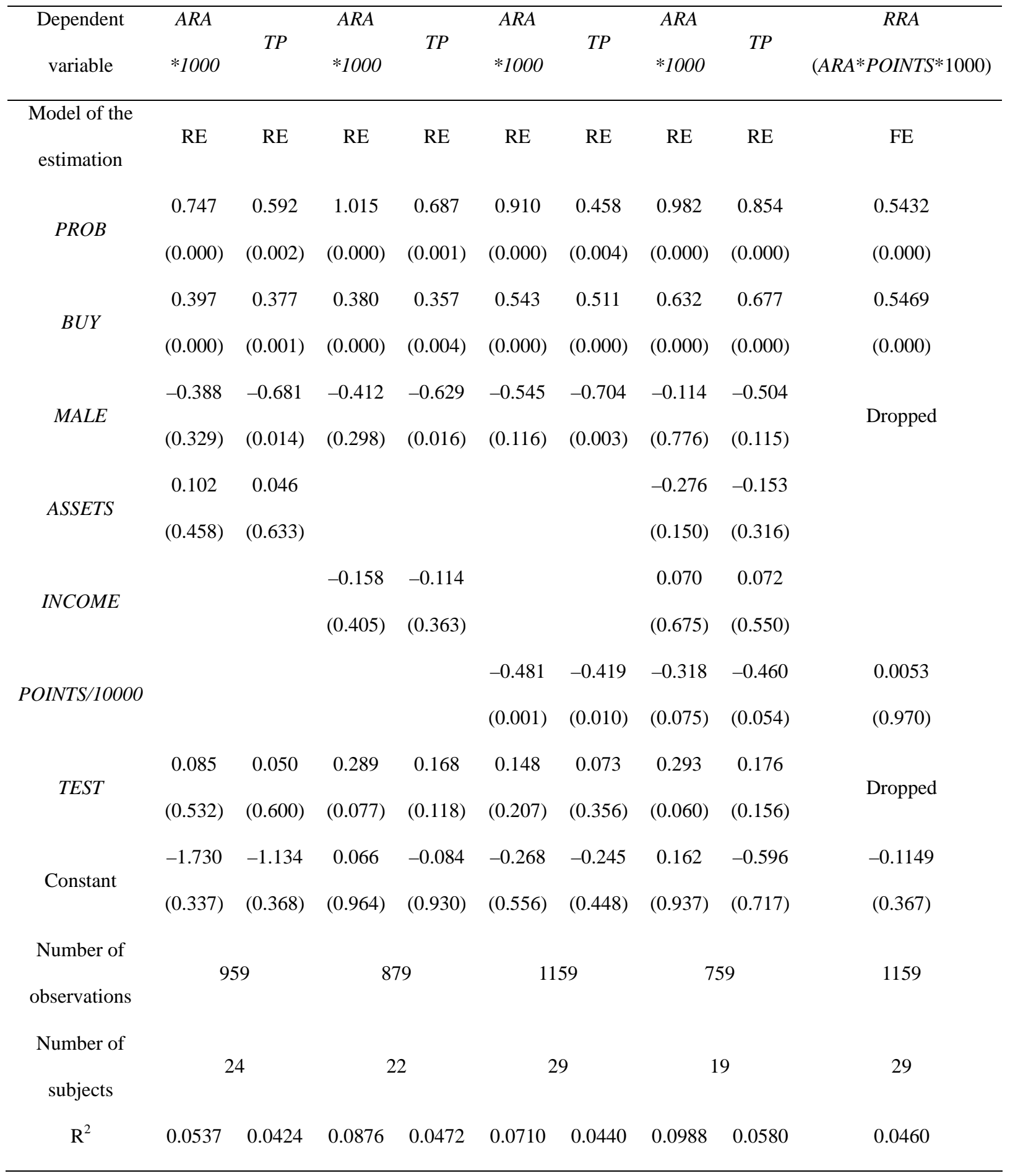

Note: $P$-values are in parentheses. RE represents random effects model; FE represents fixed effects model. Number of observations varies due to the lack of data for RISK and/or ASSETS. 
Table 5. Risky asset holdings and risk attitudes

\begin{tabular}{|c|c|c|c|c|c|c|}
\hline Dependent variable & RISK & RISK & RISK & RISK & RISK & RISK \\
\hline AVARA*1000 & $\begin{array}{c}-11.8035 \\
(0.061)\end{array}$ & $\begin{array}{c}-22.0727 \\
(0.004)\end{array}$ & & & $\begin{array}{c}-10.9523 \\
(0.088)\end{array}$ & \\
\hline ASSETS & $\begin{array}{l}8.1034 \\
(0.030)\end{array}$ & & $\begin{array}{c}-5.3120 \\
(0.519) \\
7.2039 \\
(0.066)\end{array}$ & $\begin{array}{c}-8.5712 \\
(0.349)\end{array}$ & & $\begin{array}{l}-8.4272 \\
(0.221)\end{array}$ \\
\hline FINASSETS & & & & & $\begin{array}{l}5.7523 \\
(0.151)\end{array}$ & $\begin{array}{l}3.4924 \\
(0.359)\end{array}$ \\
\hline INCOME & & $\begin{array}{l}1.4512 \\
(0.718)\end{array}$ & & $\begin{array}{l}3.3515 \\
(0.508)\end{array}$ & & \\
\hline$M A L E$ & $\begin{array}{l}13.4902 \\
(0.164)\end{array}$ & $\begin{array}{l}8.6895 \\
(0.346)\end{array}$ & $\begin{array}{l}14.2525 \\
(0.216)\end{array}$ & $\begin{array}{l}8.5020 \\
(0.501)\end{array}$ & & \\
\hline Constant & $\begin{array}{c}-81.2837 \\
(0.081)\end{array}$ & $\begin{array}{l}12.2248 \\
(0.727)\end{array}$ & $\begin{array}{c}-74.7764 \\
(0.133)\end{array}$ & $\begin{array}{c}-12.1098 \\
(0.780)\end{array}$ & $\begin{array}{c}-39.7429 \\
(0.348)\end{array}$ & $\begin{array}{r}-19.9415 \\
(0.631)\end{array}$ \\
\hline Number of observations & 21 & 17 & 21 & 17 & 18 & 18 \\
\hline Pseudo $\mathrm{R}^{2}$ & 0.0518 & 0.0815 & 0.0329 & 0.0247 & 0.0267 & 0.0159 \\
\hline
\end{tabular}

Note: $P$-values are in parentheses. Estimation method is Tobit. 
Table 6. Correlation coefficient between risk attitude in the experiment and risk attitude in the questionnaire

ARA

\begin{tabular}{|c|c|c|c|c|c|c|c|c|}
\hline & AVARA & RAIN & VENTURE & FIRE & Q13ARA & Q14ARA & Q15ARA & Q16ARA \\
\hline AVARA & 1.0000 & & & & & & & \\
\hline$R A I N$ & $0.3880 * *$ & 1.0000 & & & & & & \\
\hline VENTURE & $0.5469 * * *$ & 0.2389 & 1.0000 & & & & & \\
\hline FIRE & -0.0563 & 0.0643 & -0.0024 & 1.0000 & & & & \\
\hline Q13ARA & 0.1899 & -0.2246 & 0.2424 & 0.1007 & 1.0000 & & & \\
\hline Q14ARA & -0.0171 & 0.1437 & 0.1058 & 0.3080 & 0.0982 & 1.0000 & & \\
\hline Q15ARA & 0.1660 & 0.0197 & 0.1323 & 0.1054 & $0.5387 * * *$ & 0.0114 & 1.0000 & \\
\hline Q16ARA & 0.0409 & 0.0797 & -0.1360 & 0.1073 & -0.2953 & $-0.4129 * *$ & 0.1680 & 1.0000 \\
\hline
\end{tabular}

Note: Q13ARA-Q16ARA are ARA of each subject derived from Q13-Q16 in the questionnaire. *** stands for significance at $1 \%, * *$ stands for significance at $5 \%$, and $*$ stands for significance at $10 \%$.

TP

\begin{tabular}{|c|c|c|c|c|c|c|c|c|}
\hline & AVTP & $R A I N$ & VENTURE & FIRE & Q13TP & Q14TP & Q15TP & Q16TP \\
\hline AVTP & 1.0000 & & & & & & & \\
\hline$R A I N$ & 0.1882 & 1.0000 & & & & & & \\
\hline VENTURE & 0.1324 & 0.2389 & 1.0000 & & & & & \\
\hline FIRE & 0.2077 & 0.0643 & -0.0024 & 1.0000 & & & & \\
\hline Q13TP & 0.1948 & $-0.3590 *$ & 0.2117 & 0.1085 & 1.0000 & & & \\
\hline Q14TP & 0.1905 & 0.1427 & 0.1056 & 0.3076 & 0.1949 & 1.0000 & & \\
\hline Q15TP & 0.2374 & -0.0293 & 0.1925 & 0.0746 & $0.4586 * *$ & -0.0433 & 1.0000 & \\
\hline Q16TP & 0.2247 & 0.0861 & -0.0285 & 0.0697 & -0.2809 & $-0.4087 * *$ & 0.2531 & 1.0000 \\
\hline
\end{tabular}

Note: Q13ARA-Q16TP are TP of each subject derived from Q13-Q16 in the questionnaire. *** stands for significance at $1 \%$, ${ }^{* *}$ stands for significance at $5 \%$ level, and $*$ stands for significance at $10 \%$ level. 


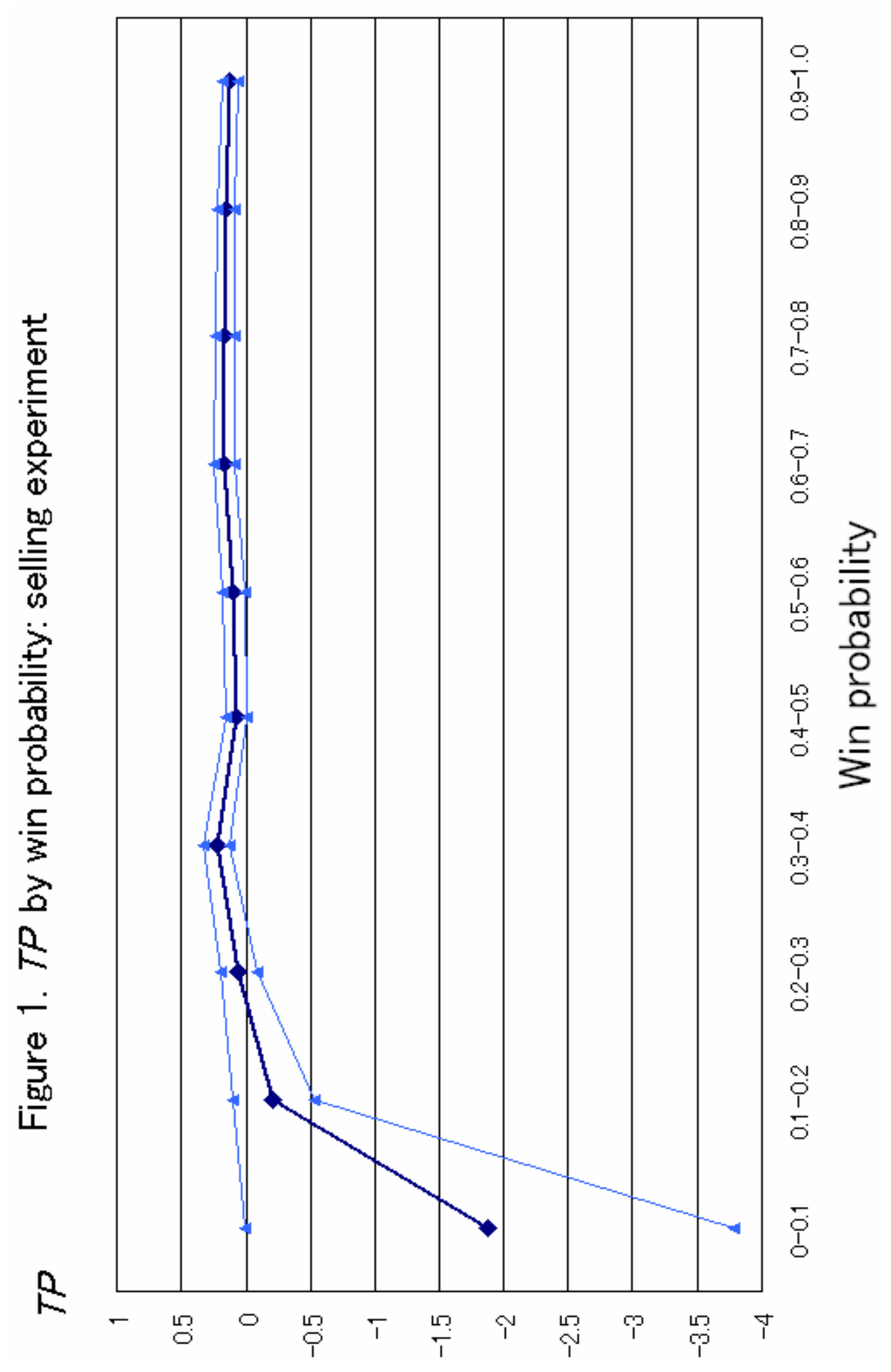




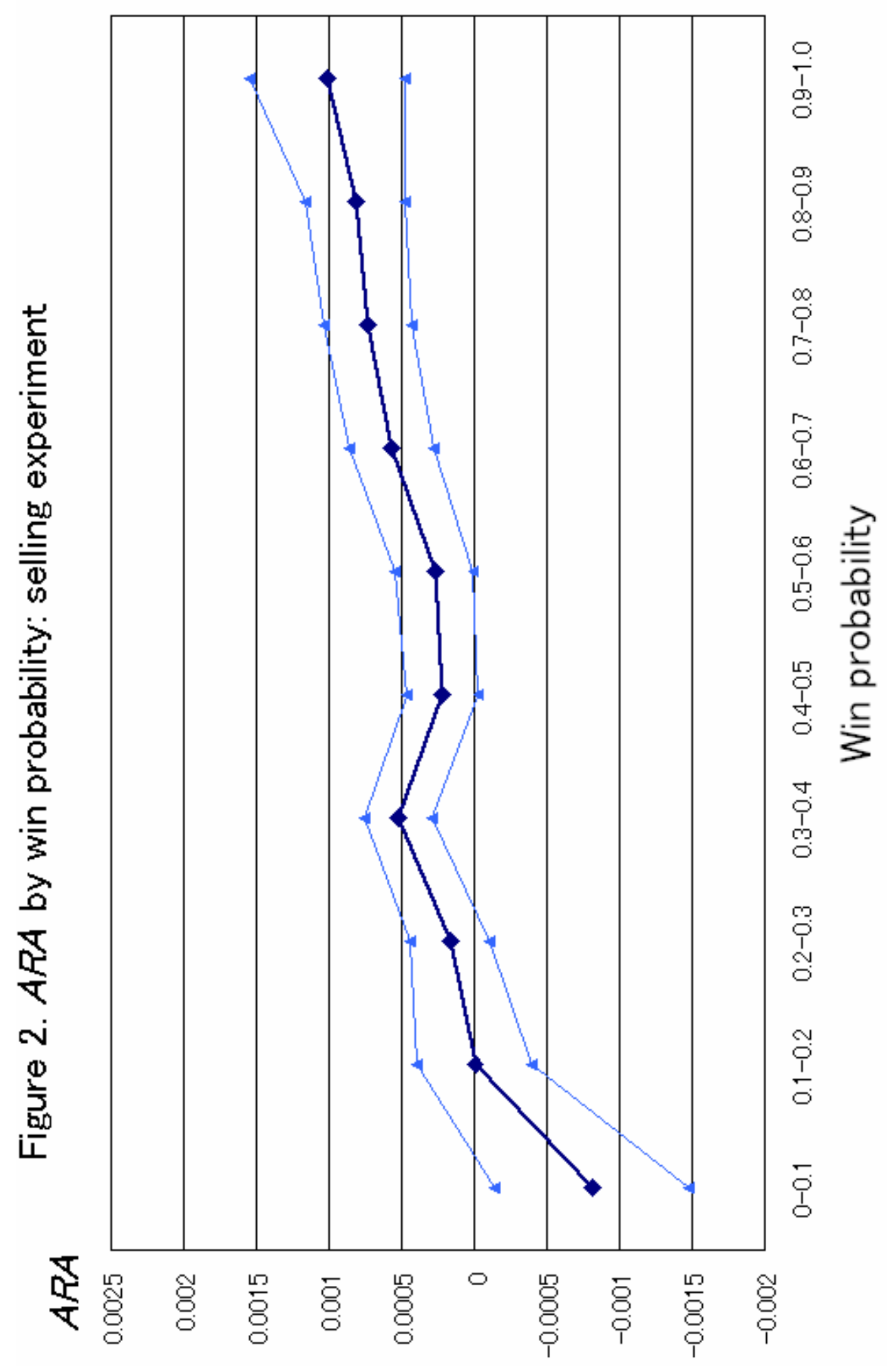




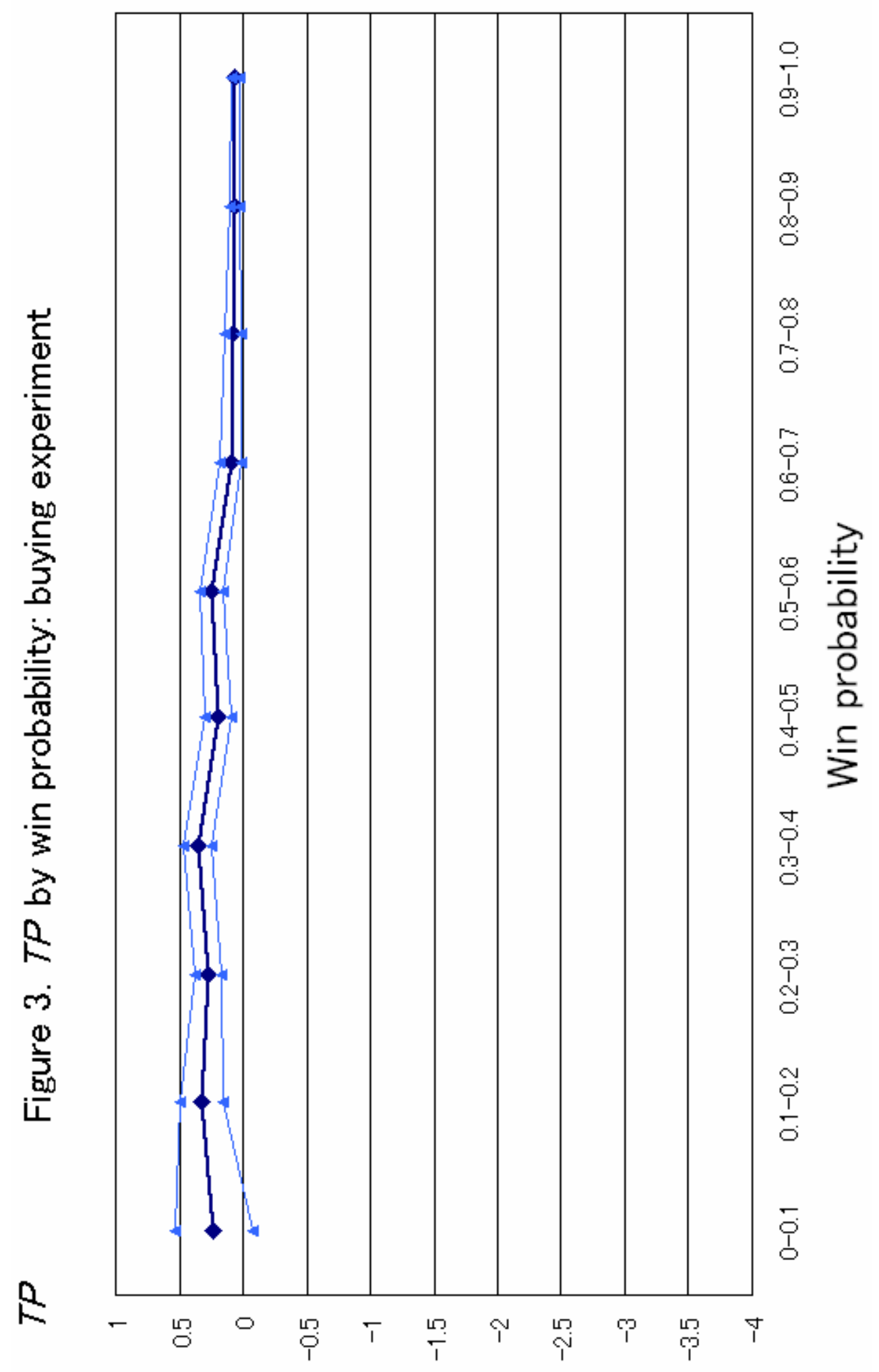




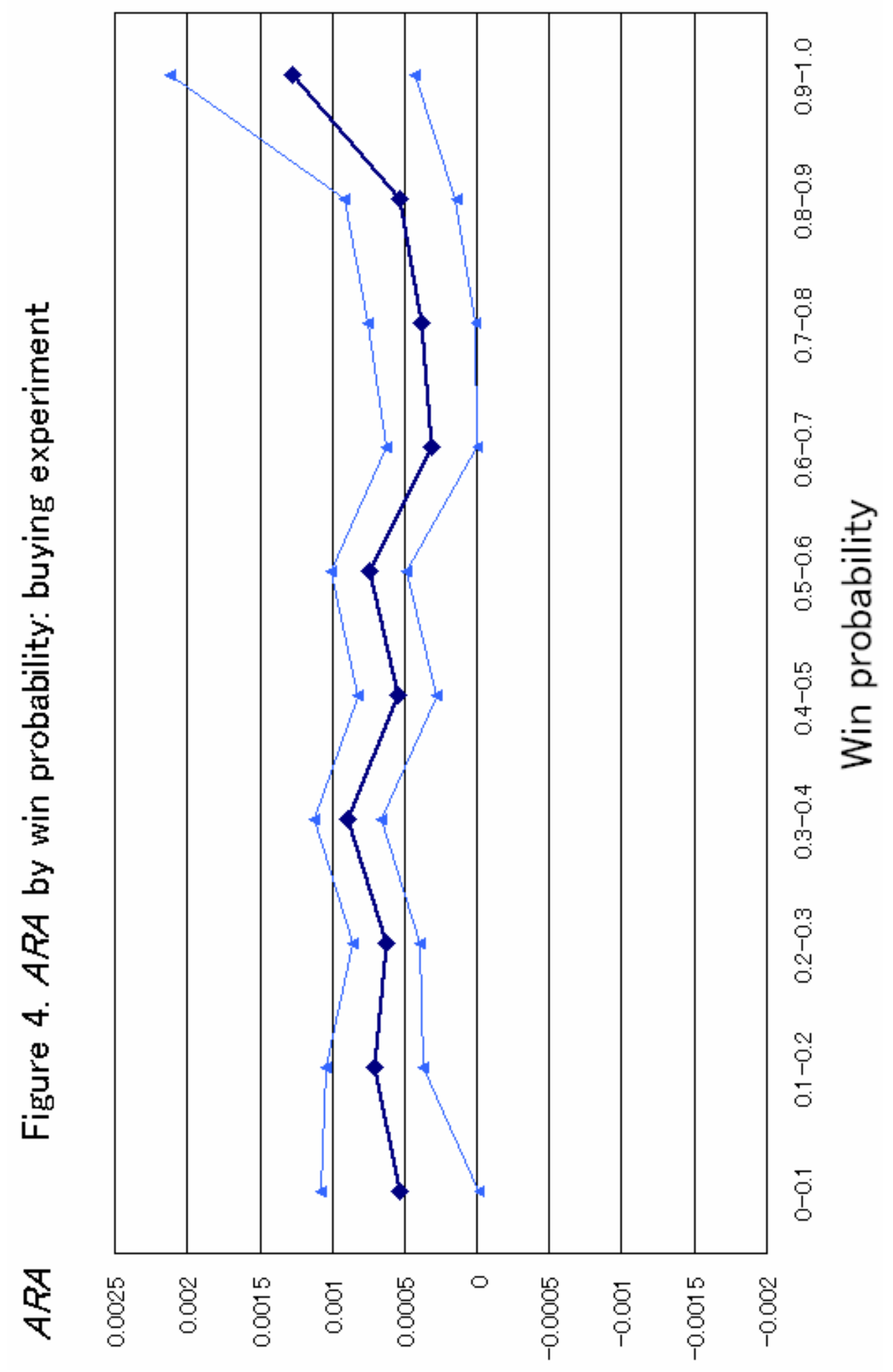




\section{Appendix A}

Questions in the Test

Instruction

To examine whether your knowledge about economics is related to the results in experiments, we ask you to answer the following questions. Your answers to the test DO NOT affect the reward you earned in the experiment. That is, your reward is not reduced if you submit incorrect answers. 
Question 1

(Quoted from Tversky, A., Kahneman, D., 1982. Judgment of and by representativeness. in Kahneman, D., P. Slovic, Tversky, A., (eds). Judgment under Uncertainty: Heuristics and Biases, Cambridge University Press, Cambridge.)

Linda is 31 years old, single, outspoken, and very bright. She majored in philosophy. As a student, she was deeply concerned with issues of discrimination and social justice, and also participated in antinuclear demonstrations.

Please rank the following statements by their probability, using 1 for most probable and 8 for least probable.

(a) Linda is a teacher in elementary school.

(b) Linda works in a bookstore and takes yoga classes.

(c) Linda is active in the feminist movement.

(d) Linda is a psychiatric social worker.

(e) Linda is a member of the League of Woman Voters.

(f) Linda is a bank teller.

(g) Linda is an insurance salesperson.

(h) Linda is a bank teller and is active in the feminist movement.

\section{Question 2}

Figure 1 depicts indifference curves for Good 1 and Good 2. Budget constraint is represented as the line AE. Under this budget constraint, at which point A, B, C, D, or E is utility maximized? Circle the correct number from the following choices. If you do not understand, circle “(1) I don’t know”. Do not guess. 
Figure 1

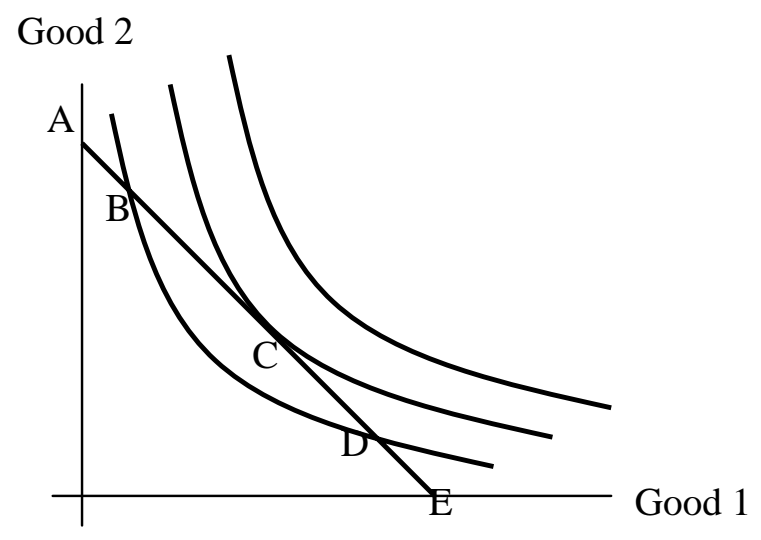

(1) I don’t know.

(2) A

(3) B

(4) C

(5) D

(6) $\mathrm{E}$

Question 3

Why do people purchase insurance? Circle the correct number from the following choices. If you do not understand, circle “(1) I don’t know”. Do not guess.

(1) I don’t know.

(2) Because they are risk averse.

(3) Because they are risk neutral.

(4) Because they are risk loving. 
Question 4

Suppose a lottery offering 80 yuan with a 50\% probability of winning and a 50\% probability of losing. What is the expected payoff and variance of this lottery? Calculate the answers and fill them in the following blanks. If you do not understand, leave them in blank. Do not guess.

Expected payoff

Variance

Question 5

If a person purchases a ticket in the lottery in Question 4 at a price above the expected payoff, is this person risk averse, risk neutral, or risk loving? Circle the correct number from the following choices. If you do not understand, circle “(1) I don’t know”. Do not guess.

(1) I don’t know.

(2) Risk averse.

(3) Risk neutral.

(4) Risk loving. 
Question 6

Figures 2 and 3 depict the utility function for two different types. Circle the number of correct combinations from the following choices. If you do not understand, circle "(1) I don’t know”. Do not guess.

Figure 2

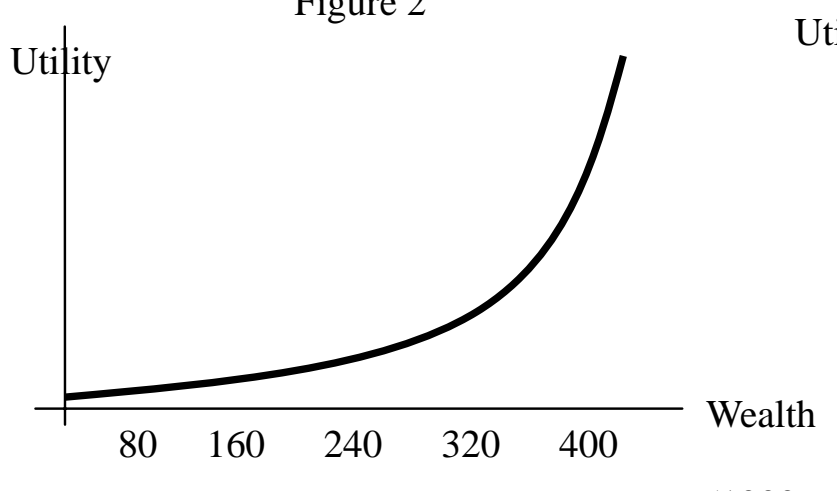

(1000 yuan)
Figure 3

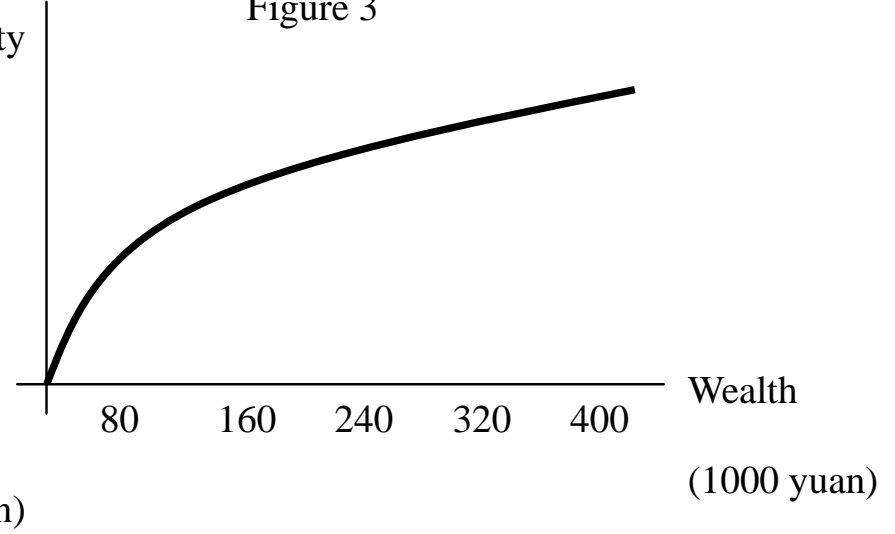

(1) I don’t know.

(2) A person who has the utility function in Figure 2 is risk averse; and A person who has the utility function in Figure 3 is risk neutral.

(3) A person who has the utility function in Figure 2 is risk averse; and A person who has the utility function in Figure 3 is risk loving.

(4) A person who has the utility function in Figure 2 is risk loving; and A person who has the utility function in Figure 3 is risk averse.

(5) A person who has the utility function in Figure 2 is risk loving; and A person who has the utility function in Figure 3 is risk neutral. 
Results of Test

Summary statistics of score

\begin{tabular}{ccccc}
\hline Observation & Mean Score & Std Dev. & Min & Max \\
& & & & \\
\hline 29 & 3.690 & 1.039 & 2 & 6
\end{tabular}

Full score is 7.

Histogram of test score

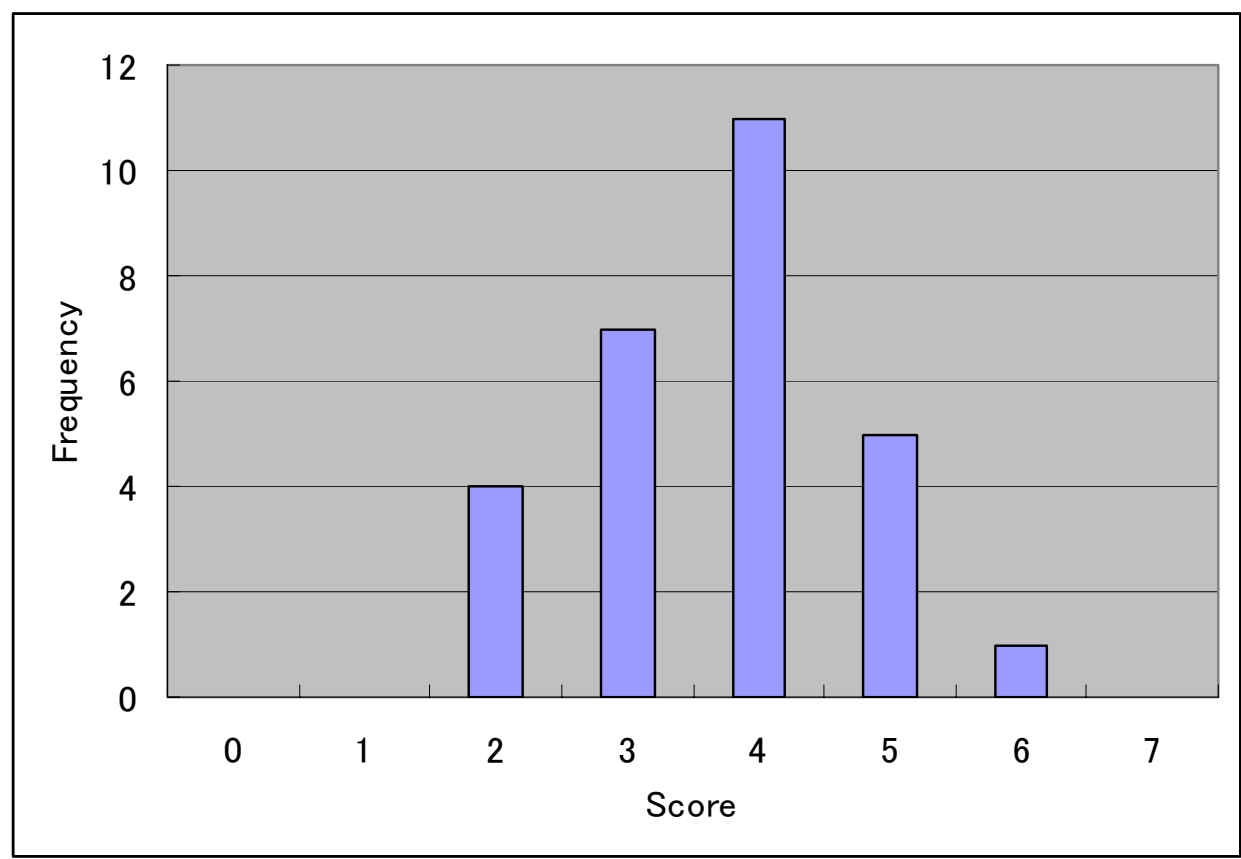




\section{Appendix B}

\section{2 pairs of $(u, x, y)$}

\begin{tabular}{rllll}
\hline & $u$ (yuan) & $x$ & $y$ & prize \\
\hline 1 & 2800 & one month & four months & no pay \\
2 & 240 & one month & four months & pay \\
3 & 240 & one month & 13 months & pay \\
4 & 240 & ten months & 13 months & pay \\
5 & 2800 & two days & nine days & pay \\
6 & 2800 & 90 days & 97 days & pay \\
7 & 2800 & one month & four months & pay \\
8 & 2800 & one month & 13 months & pay \\
9 & 2800 & ten months & four months & pay \\
10 & 800000 & one month & four months & no pay \\
11 & 800000 & one month & 13 months & no pay \\
12 & 800000 & ten months & 13 months & no pay \\
\hline
\end{tabular}

